\title{
VORGES - A Procedural Model for Total Ship System Engineering Developed by MTG MARINETECHNIK
}

VORGES - Un modelo procedimental para el sistema de ingeniería total de embarcaciones desarrollado por MTG MARINETECHNIK

André Neumann ${ }^{1}$

\begin{abstract}
Naval vessels are highly complex and sophisticated systems. The core issue concerning the planning of a future naval vessel is to identify operational needs, respective requirements and corresponding technical solutions, which are affordable in line with the budget. Due to the complexity of a naval vessel, it is impossible to answer this question by assigning a specific amount of money to a specific requirement. To address this issue, MTG developed the procedural model for total ship system engineering - called VORGES (VOrgehensmodell GEsamtentwurf Schiff) - that starts in the very early planning phase, enabling the procuring authority to generate a reference design that balances functional and technical requirements with the available budget. VORGES is an iterative and flexible process of continuous evolution that additionally involves the customer and end-user. With respect to user requirements, VORGES includes the generation of several conceptual and preliminary designs at different detail levels. The resulting design alternatives will be evaluated and compared against each other for critical factors like life cycle costs, project risks, military performance or requirements fulfilment. This will enable the procuring authority to make a comprehensive decision for the optimum design at the highest efficiency level of budget expenditure, hence, resulting in the formulation of the technical requirements for procurement.
\end{abstract}

Key words: Model, Total ship system engineering, planning.

\section{Resumen}

Las embarcaciones navales son sistemas altamente complejos y sofisticados. El asunto central en cuanto a la planeación de una futura embarcación naval es identificar las necesidades operacionales, los requerimientos respectivos y las correspondientes soluciones técnicas, que sean asequibles en línea con el presupuesto. Debido a la complejidad de una embarcación naval, es imposible responder esta inquietud mediante la asignación de una cantidad específica de fondos a un requerimiento específico. Para abordar este asunto, MTG desarrolló el modelo procedimental para el sistema total de ingeniería de la embarcación - denominado VORGES (VOrgehensmodell GEsamtentwurf Schiff) - que inicia en la fase temprana de planeación, permitiéndole a la autoridad de adquisiciones a generar un diseño de referencia que equilibre los requerimientos funcionales y técnicos con el presupuesto disponible. VORGES es un proceso iterativo y flexible de evolución continua que adicionalmente involucra al cliente y al usuario final. Con respeto a los requerimientos del usuario final, VORGES incluye la generación de varios diseños preliminares y conceptuales en diferentes niveles de detalle. Las resultantes alternativas de diseńo se evaluarán y compararán entre sí para identificar factores críticos como costos de ciclo de vida, riesgos del proyecto, rendimiento militar o cumplimiento con los requerimientos. Esto le permitirá a la autoridad de adquisiciones tomar una decisión integral para el óptimo diseńo al más alto nivel de eficacia de gasto de presupuesto, entonces, resultando en la formulación de los requerimientos técnicos para adquisición.

Palabras claves: Modelo, Sistema de ingeniería total, Planeación.

Date Received: December 13th, 2012 - Fecha de recepción: 13 de Diciembre de 2012

Date Accepted: February 7th, 2013 - Fecha de aceptación: 7 de Febrero de 2013 


\section{Introduction}

Changing geopolitical and economic conditions entails a major impact on the planning process of naval vessels. Planning and construction of Navy ships was in the past mainly dominated by a few nations, for both national demand and for export. The steady growth and increasing self-awareness of emerging countries lead to nationalization of both the planning and construction processes. While this trend is reinforced by the increasing demand of naval vessels, it also implements the request to increase expertise in the local market, as well as to consider national tactical and operational characteristics in the planning of future Navy ships to a maximum extent.

In most cases, the available defence budget for a certain typically top-prioritized and highbudgeted project is not sufficient enough to find the one and only design meeting all naval requirements. Therefore, it is of utmost importance to spend the allocated budget as efficiently as possible. In the late 80 s, VORGES was developed as a methodology, tool, and procedure to specify a reference design for naval warships that balances the budget and naval requirements, enabling the procuring authority to formulate the technical specifications for the tender and building processes. It has since become the standard procedure to support the planning process of the German Navy for all types of surface vessels. As a result of the VORGES procedure, the procuring authority will be able to determine the required budget, as well as to procure the optimum naval vessel for their fleet. It is a one-stop service, finding affordable solutions by:

- Consolidating user requirements into feasible requirements,

- Creating meaningful sets of requirements,

- Developing a variety of possible ship designs,

- Estimating procurement and life-cycle costs,

- Calculating effectiveness measurements by simulation,

- Assessing the results in relation to the requirements.

Additionally, VORGES is being used to answer "what-if" questions with respect to the influence of the budget. It means, in detail, that VORGES can investigate different technical solutions and their budgetary influence without the requirement to generate a complete design. This investigation must, thereby, be done on the basis of a base design. Especially during the Multirole Combat Ship Class 180 (MKS180) process, this procedure was of high value to answer questions related to different configurations or policies (e.g., different speed profiles, different manning concepts) in a very short time.

The VORGES methodology can be briefly described as an iterative process of standardized phases requiring expert knowledge, up-to-date databases, state-of-the-art CAE/CAD tools, and broad cooperation within the network, as well as active participation of the end-user.

As a basic framework, the planning process can be separated into two major steps. During the first step, the elaboration of several conceptual designs during a very short period, on the basis of generating a broad choice of different vessel designs, provides sufficient information for an initial selection process of one or more promising designs that meet the initial functional and budget requirements. After the selection, one or more preliminary designs will be created in high detail, enabling the procuring authority to determine the required technical specifications. Both steps are subdivided into further phases that can be described as a circular and iterative sequence of activities. By iterating this sequence, a promising design can be found by using the results of iterations to improve the accuracy of user requirements and use the modified requirements as an input for the next iteration.

A profound, in-depth description of this complex methodology is difficult within the framework of this paper. Therefore, the following paper will focus on the overall procedure, providing a thorough introduction of the VORGES process, the steps involved, and tools required. 
Fig. 1. Circle of VORGES activities

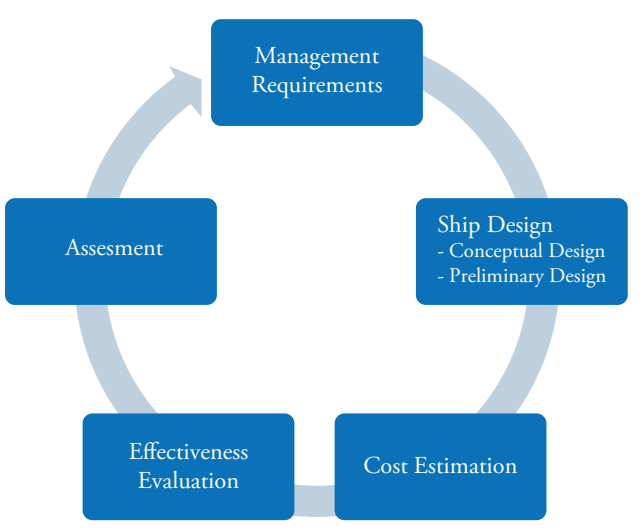

\section{Design Process}

To close the identified gap of military performance and/or capability with respect to the operation of naval vessels, the procuring authority basically has three possibilities:

- Design and procure a new vessel (that also includes the modification of existing designs),

- Procure an existing design,

- Modify/upgrade/downgrade an existing vessel.

Either process requires thorough analysis as to what extent the gap can be bridged within the available budget or how the gap can be closed at the optimum cost-benefit ratio if there is no existing budget restriction. For this purpose and independent of the acquisition strategy, generation of a design is essential to allow the procuring authority to make a substantiated decision.

\section{Conceptual Design}

The conceptual design phase of the VORGES process is subdivided into eight phases. These phases are usually not processed sequentially. Dependent on the required design, it is also possible to elaborate several phases in parallel and to repeat already finished phases if the results of other preceding phases dictate. Fig. 2 provides an overview of the sequence and the dependences of the overall process.

\section{Phase 1: Analysis of user requirements}

The VORGES process starts with the analysis of the customer requirements. Usually, at an early stage of procurement planning, the procuring authority already has a set of specific formal requirements. These requirements often focus on procurement costs, engineering standards, documentary standards, and operational requirements for the total system. Experience shows that most customers also have a significant number of non-specified expectations for their future naval vessel. Therefore, an extensive dialog between the design authority and the procuring authority is essential to prepare the initial set of requirements.

The analysis process focusses on the clarification of the technical feasibility, as well as on the definition of the weighting of the different requirements, given that usually different weightings exist. On the basis of the set of requirements, the so-called hierarchy for benchmarking and prioritization can be defined by using the "Expert-Choice" tool, which was designed for complex decision making. With this hierarchy, the conceptual designs can be evaluated; this will be done at a later stage.

Simply using this stage as a pure analysis part is misleading. Over the course of the planning process, several circumstances or parameters like budget adjustments, change of the political preferences, and insights gained from other designs will influence the overall process. The more mature and detailed a vessel design becomes, the deeper the inherent technical and operational complexities can be evaluated. This regularly leads to the discovery of conflicts or contradictions among requirements.

Sometimes, this also requires updating and changing initial requirements that entail a sustained influence on the following planning process.

Therefore, VORGES handles these circumstances through a continuous requirements management process that takes care of:

- The analysis of the customer requirements,

- Supporting and consulting the customer/ change and quality management,

- Dealing with / prioritizing conflicting 
Fig. 2. Flowchart of conceptual design process

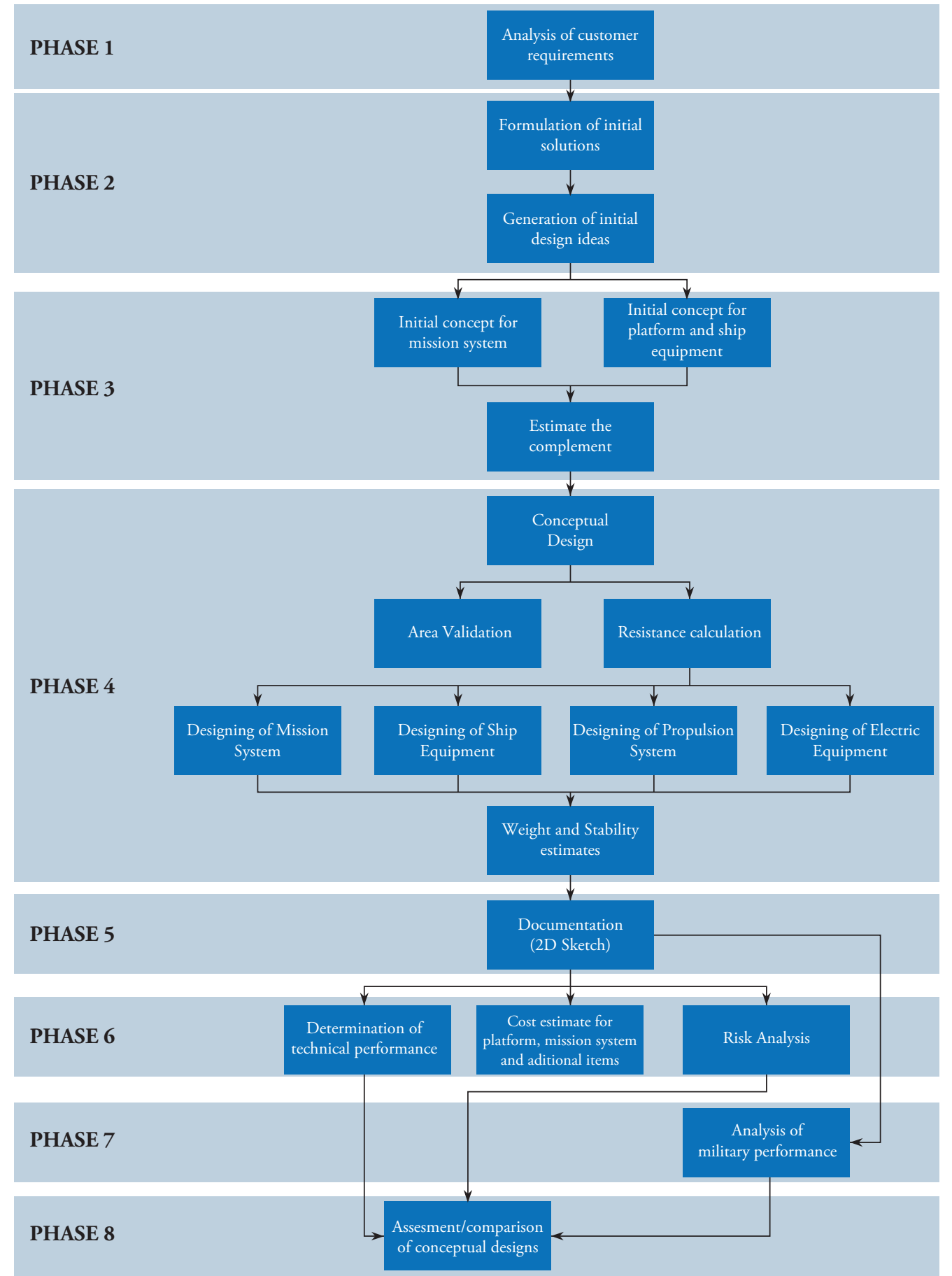

requirements,

- Processing results from iterative conceptual designs into the requirements for future designs,

- Reducing complexity by structuring the requirements,
- Consolidating requirements into usable sets for vessel designs.

On the basis of the initial meaningful set of requirements, the initial planning process can be continued. 
Phase 2: Formulation of initial solutions and design ideas

This phase is - based on the requirements defined - a first step to find initial ideas and solutions that meets a maximum of requirements. At this stage, ideas that document the various focal points that must be considered when implementing the requirements into technical solutions will be coordinated and documented. Due to limited budgets, it is usually not possible to implement all requirements into one technical solution. However, in most cases, it will also be very interesting for the procuring authority to gain an indication of the level of budget overrun. The initial solution gained describes a logical, meaningful and self-contained part of the defined customer requirements. This initial solution can be pictured as a filter through which the requirements are poured. Some requirements pass through completely, some partly, and others are withheld. The requirements found by using this methodology are called "Basic Requirements". These basic requirements will now be implemented into technical solutions that form the basis for the various possible design ideas, which include first details on the implementation of the individual requirements. It outlines, for example, the required number and types of ships and describes first technical solutions. On this basis, the technical design process can be started.

Phase 3: Development, generation, and adaption of building blocks and operational concepts

The technical implementation of different design ideas, as mentioned, is mainly done by finding the combination of building blocks meeting the basic requirements. Having different or competing building blocks will lead to further solutions and broaden the set of alterations and solutions, hence, significantly increasing the overall processing complexity.

As a general rule, a building block is built up from objects, which provide technical, functional, and cost data. The technical data are derived from components containing information like weight, volume, dimension, and electrical data. So-called "Payloads" will generally provide information with respect to costs and additional requirements for operation. Functional objects hold standardized functions as attributes for surface ships, e.g., air defence. The basis to use the MTG planning software is the definition of the basic characteristics of the mission system, as well as of the platform that is being specified in detail in building blocks. To generate a high amount of conceptual designs in a short period of time, it is essential to have all building blocks available, up-to-date, and adjusted to the project. This implies the dependency to have a close cooperation with the naval industry and to actively participate in the network of naval design organizations.

The overall aim of this phase is to:

- Designate building blocks for the mission system,

- Designate building blocks for the platform and the ship equipment

- Find an estimate for the complement.

Based on the required capabilities (e.g., ASW, ASuW, etc.) a list of basic technical requirements is generated. Based on this list of required technical functions, the responding building blocks can be designated to generate the initial concept for the mission system.

During this stage, the designer is responsible for picking the optimized set of building blocks from an overall catalogue of building blocks. In case of conflicting solutions, it might also be possible to think about having several competing designs reflecting different combinations of building blocks that meet the basic requirements. The selection and combination of the preferred building blocks have to be done in close cooperation with the experts responsible for the platform design, ship equipment design, and electrical design to get an overall concerted system. The result of the building blocks selection will be documented in the mission system sketch containing a basic diagram of the arrangement of the mission components.

Building blocks for the ship equipment can be designated on the basis of a combination of the information of the layout of the mission system and preconfigured standard platform concepts. Information being recognized and designated 
Fig. 3. Definition of building blocks

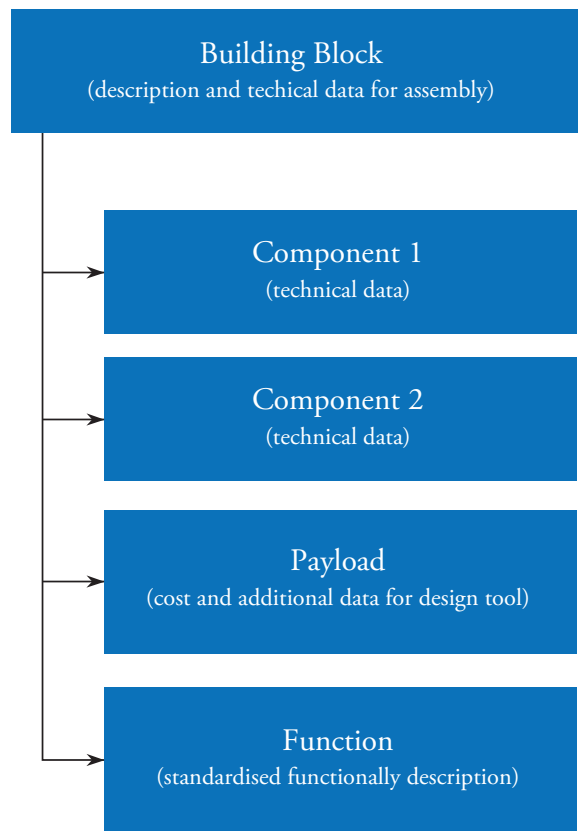

during this step is:

- Type and class of vessel, ship equipment and technology,

- Hull form characteristics,

- Mobility, endurance, complement, required reserves.

The third step during this phase is the designation of the required manning for the overall system. Inputs will be taken from figures for preconfigured concepts for the different warfare areas, as well as from information with respect to:

- Approximate displacement

- Endurance

- Max speed

- Approximate length of the vessel

- Degree of automation (fixed factors)

- Maintenance concept

- Modular mission systems

- Planned detachments

- Watch cycles and routines

- CIC configuration

Based on the aforementioned inputs, the initial manning concept for planning can be formulated, but needs to be constantly adjusted during the ongoing design process with more precise information available.

\section{Phase 4: Conceptual design}

With the first concepts of the corresponding mission system formulated, platform layout, designated building blocks for ship equipment, and resulting complement the conceptual design phase can be started to generate numerous variants of naval vessel designs incorporating the results of phase 3 in a short time frame.

The design process will be supported by the following software tools developed by MTG:

- Ship Design Programme (SVEP)

- Object Oriented Data Base System.

Furthermore, major commercial design tools like CAD-Systems for 2D/3D designs, hull design and hydrostatic software, CFD programmes for power prediction, as well as office tools for calculation and documentation are also being used, especially at a later stage during the Preliminary Design Phase.

The objective of the calculation and iteration in the conceptual phase is to create balanced ship designs with reference to parent hull forms, modelled on volume and mass calculations. The program uses a design algorithm with specific determinants for naval vessels, naval auxiliaries, and commercial vessels resting upon statistical analyses of consisting vessels. Fig. 4 displays a schematic diagram of the inputs and outputs of the SVEP computation.

A large part of the required input data is provided by the Database System as objects, which are called "Building Blocks" as described previously herein.

On the basis of the elaborated requirements, the ship designer starts looking for the corresponding building blocks by screening the linked functions. Afterwards, the main platform objectives like number of ships in class, ship type, endurance, speed, etc., will be set. The preparation of a rough drawing is necessary to estimate the main dimensions and to arrange the components that have a strong effect on them. Some information from the first sketch is also important for estimating the $\mathrm{B} /$ T-ratio (beam/draught) and the coefficient of fineness. 
Fig. 4. Schematic diagram of SVEP computation

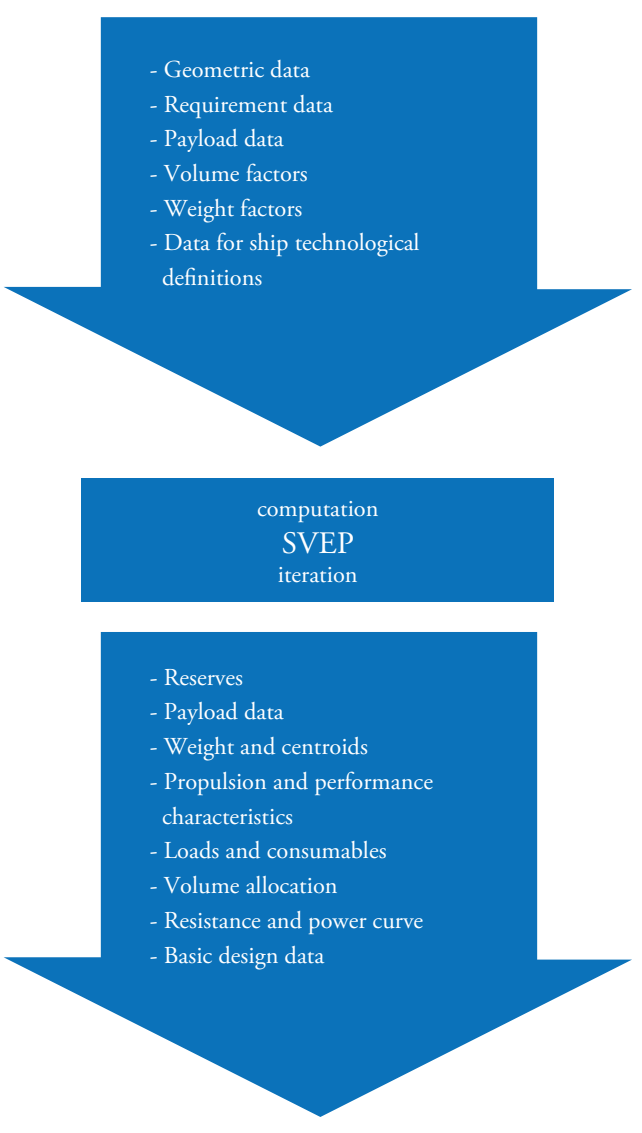

The rough drawing is not only for pre-estimating input data, but it is also used to evaluate the result of the Ship Design Program.

SVEP gets the technical data and the payload data from the database system. As a result of computation, SVEP generates, to name but a few, essential information like:

- Main dimensions,

- Displacement,

- Form coefficients,

- Volume allocation,

- Stability values,

- Propulsive power curve,

- Weights and centres of gravity,

- Machinery installations,

- Electrical installations,

- Weapons installations,

- Communication and sensors,

- Hull and superstructure,

- Technical equipment.
Simultaneously to the drawing preparation, the results will be validated. Important is the review of weight and centre of gravity by means of a more detailed weight estimation. The weight results of SVEP are rechecked here on the basis of built naval vessels or by using different wellestablished calculation methods to estimate the weight of each component. For a first stability analysis an adapted hull form from a hull library is used. In this stage of the design it is sufficient to prepare a rough lines plan, which is scaled in order to obtain the hull-coefficients and main dimension. Similar methods are used to validate the propulsive power and electrical power.

\section{Phase 5: Documentation of conceptual design}

After running the computation, the next step is the preparation of a drawing, composed of a side view, a top view, and an above water side view.

In reference to the results, the main dimensions and values like frame spacing, number of sections, position of bulkheads, and outline of hull and superstructure will be determined. This is followed by arranging the main components that have a strong effect on the design, e.g., essentially horizontal and vertical main passage ways, stairwells, propulsion plant, exhaust pipes, switch boards, and -if required- helicopter facilities, cargo holds, RAS equipment, stern ramps and recesses for RHIBs. The main components of the required combat system, e.g., weapons, sensors, and communication systems will also be arranged.

The technical part of the Conceptual Design results in the $2 \mathrm{D}$ sketch accompanied by the following information:

- Main dimensions,

- Propulsion concept,

- Electric concept,

- Payload components (including mission concept).

Increased accuracy of technical solutions can be achieved by developing Preliminary Designs at a later stage in the process. 
Fig. 5. Flowchart of conceptual design process

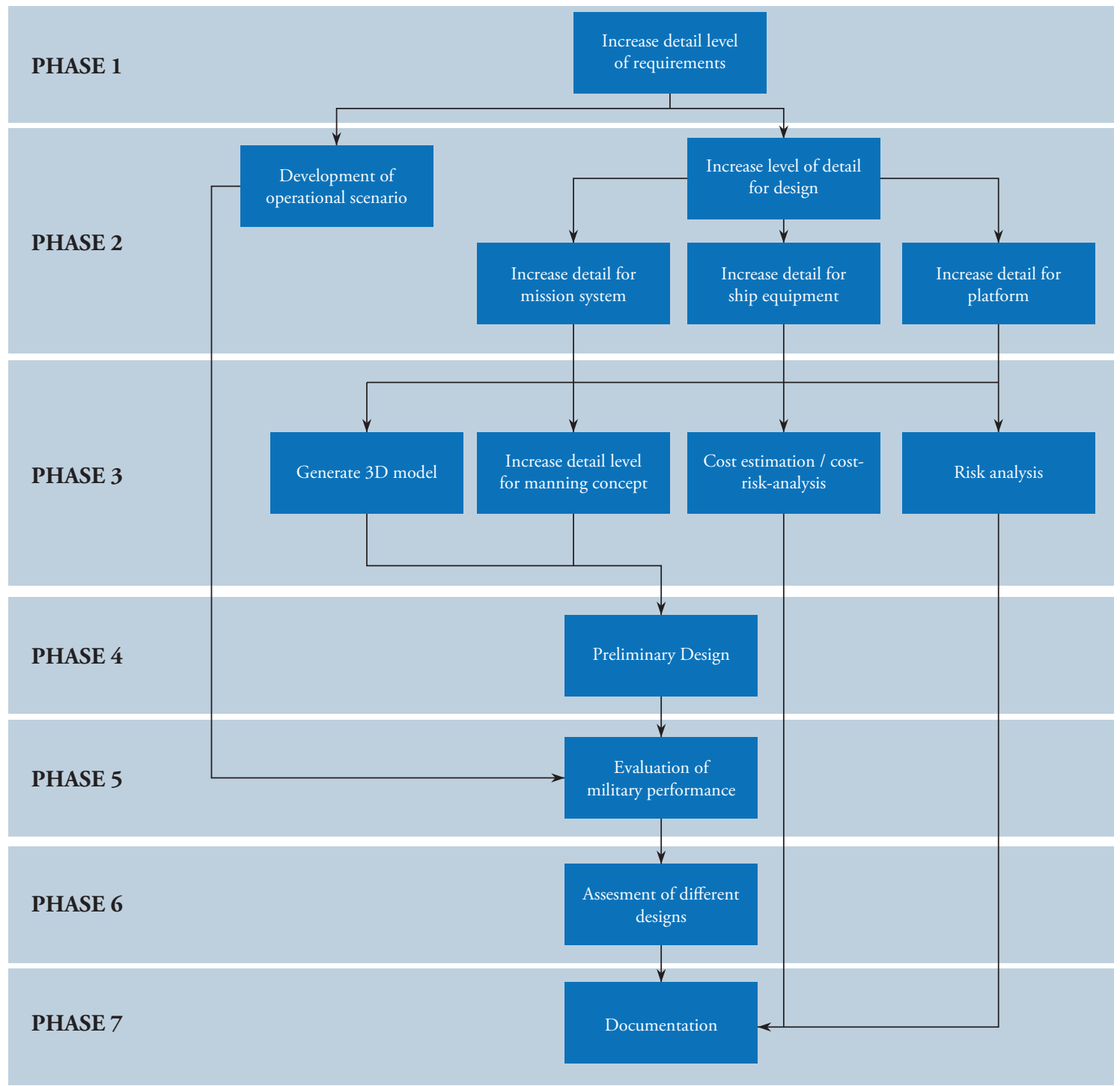

Phase 6: Determination of technical the cost estimation at this stage to get a qualified performance, costs, and risks

It is important to start the determination of the technical performance and the first cost estimation at this early stage to decide whether to proceed or to iterate in order to generate further designs.

Determination of the technical performance is done by a simple comparison of elaborated data with requirements set in the initial stage of the design process.

Based on the design regulations (design to budget, design to requirements), it is also essential to start statement of the most probable costs. A constant cost evaluation during the project is essential to:

- Define the budget funds,

- Validate different alternatives,

- Evaluate tenders and select economically reasonable solutions,

- Identify cost savings or potential for economy,

- Reduce risk.

The cost estimation process is subdivided into seven steps:

- Set up project,

- Define work breakdown structure (WBS), 
- Choose estimation model,

- Generate cost estimate,

- Review and validate estimate,

- Perform cost risk analysis,

- Document estimate.

The cost estimation project is initiated by collecting technical, programmatic, and cost data. Additionally, it is required to adjust the accounting data for inflation, learning, and quantity. Furthermore, the acquisition strategy (competition, consortium) has to be gathered. Typical sources of data are: cost proposals of vendors, historical databases, governmental agencies (the customer), experts, and open source (Internet, Naval reference books). In addition, necessary assumptions (e.g., inflation, wages, overheads) are identified in this step.

The next step is the definition of the WBS elements that will be derived from the conceptual design and as previously specified. A WBS, thereby, is a decomposition of the ship into smaller components or rather functional technical groups like hull structure, propulsion plant, electric plant, etc.

The selection of the estimation model depends on the current phase of the project. For cost estimating purposes, every future naval vessel is divided into platform and payloads. Two models are used in VORGES; one for the very early conceptual design phase (SCEM - Ship Cost Estimation Method) and one for the preliminary design phase (GELIMAKO - GEräteLIste MArineKOsten (Cost register of naval equipment)). Both models are the property of MTG Marinetechnik as no COTS software is available for this kind of estimation task. Both SCEM and GELIMAKO apply a combination of the previously mentioned methods. The main SCEM method is a parametric top-down estimation with Cost Estimating Relationships (CERs). The data points collected over the course of time are connected via polynomial or cubic spline interpolation. Parametric estimation is used for platform cost elements like hull, propulsion, and electric plant. Accordingly, independent variables like hull volume, installed propulsion, number, and kind of propellers or power of electric plant are used. It is not easy to generate CERs for payloads, so expert opinions and analogies are used. Engineering costs for design and construction, management, proofs, test and trials along with others are estimated via empirically found formulas. Typical parameters in these formulas are number of building yards involved, number of ships, installation costs of payloads etc. The SCEM is usually used for rough estimates and "what if"-questions.

After the input of all necessary data, the model generates the cost estimate at the push of a button. This always goes along with a review and validation of the estimate. Reviewing means to cross-check the overall estimate with historical projects to see if the results are plausible. Implausible results lead to a revision of all input data and to one or more re-runs of the estimation.

After the cost estimation, a cost risk analysis (CRA) is performed to consider and evaluate the uncertainties in the model and the input data. As a result of the CRA, confidence will be achieved as to what extent the budget will be met; over- or underrun will be determined. This essential information for the Project Management is rendered by a comprehensive approach to analyse available or new technical details and solutions, as well as other factors related to political and economic issues.

Aside from aforementioned, as a standard procedure in the German procurement process, an economic feasibility study has to be made, looking for an economically reasonable solution by investigating costs, available technology, and risks involved.

Finally, the estimate is documented and presented. The documentation compiles the assumptions made, the estimation methods used, and the main results such as cost per WBS group and total system costs.

Phase 7: Determination of militaryperformance As soon as the technical evaluation and cost estimation is finished, various conceptual designs will be evaluated for their military performance by using a Maritime Scenario Simulation Tool (MaSST). The MaSST software is a highly customisable simulation framework for tactical 
scenarios. It is based on a COTS professional simulation environment, which was originally designed for tactical land scenarios. For VORGES, the MaSST software environment was significantly enhanced with several proprietary add-ons for tactical maritime scenarios. The base software, combined with the add-ons for maritime operations, results in a simulation environment with blue-water and superior brown-water scenario capability.

The add-ons include, among others:

- Radar sensor simulation module,

- IR sensor simulation module,

- Gunfire simulation module,

- Missile simulation module,

- Surface ship kinematics module,

- Vessel generator module.

To collect and analyse the data generated by MaSST simulations, various data logging modules have been developed and integrated into the simulation environment.

By original design, MaSST is not a ready-made or turnkey tool, but instead a modular system, continuously growing and enhanced for new specific tasks. If required, MaSST can simulate all tactical maritime environments of a particular vessel design. In principle, all kinds of maritime operations can be created and represented, ranging from harbour protection scenarios - which do not require a large ops theatre but a very high level of detail instead- to complex sea/land or air/ sea/subsurface multi-threat scenarios, including large-scale sea surveillance scenarios in which the operations theatre can easily measure thousands of square nautical miles. However, future development of MaSST will be focussed on the creation of a range of predefined simulated tactical scenarios, e.g., for sea surveillance.

Today, the tool is already used to:

- Create and evaluate operational concepts,

- Determine key parameters for future naval procurement programmes,

- Compare different concepts for maritime operations,

- Determine the military capabilities of naval vessel designs.
Testing a naval vessel design in a simulated tactical environment during the early stage of planning and procurement yields several advantages, e.g., design changes are possible at relatively low costs (compared to changes during later stages of the procurement process). Results from MaSST for a range of predefined and/or customised simulated tactical scenarios may also be included into the requirements for the vessel, enabling the procuring authority to specify design requirements grouped along different scenarios. Thus, complexity is reduced at an early stage of the procurement process. The results from the MaSST simulations can be fed back into the ship design process. This empowers the procurement project manager to balance operational restrictions and cost restrictions more efficiently.

\section{Phase 8: Assessment of conceptual designs}

Because multiple vessel designs for selection by the procuring authority have been created, the requirement for an unbiased and objective assessment methodology arises. In order to have an equitable and consistent framework to compare different designs with regards to the requirements, an evaluation hierarchy has been established within VORGES by applying the Analytic Hierarchy Process (AHP) using the COTS "Expert Choice" software tool.

The basic idea of AHP is pairwise comparison, which means that both sub-criteria and alternatives to be evaluated are compared pairwise and rated by means of a pre-defined scale. In principle, all possible pair combinations are considered and rated individually. This may result in a relatively high amount of pairwise comparisons; for 3 criteria to be compared, 3 pairwise comparisons need to be made, but for 25 criteria we arrive at 300 pairwise comparisons. Accomplishing pairwise comparisons results in a matrix that is transformed into a weighting/benchmark for the constituent criteria/alternatives. Pairwise comparisons are executed by using the so-called AHP scale.

This scale consists of values between the extremes, defined as follows:

1 equally relevant

3 slightly more relevant 
In each pairwise comparison, one of the designs is assigned the appropriate value from the above scale to express its significance/weighting/suitability in relation to the other candidate in that pair.

As a result, the AHP methodology produces a ranked order of the different conceptual and, at a later stage, preliminary designs based on the procuring authority's requirements, which have been weighted.

The assessment phase concludes with an evaluation of the degree of requirements fulfilment in the different conceptual designs. It will be evaluated if there is at least one design meeting basic requirements. This will lead to the decision whether to continue the process and to start the preliminary design or to restart the conceptual design phase.

\section{Preliminary Design}

From the catalogue of different conceptual designs, the procuring authority and/or the end-user has to select one or more promising solutions that will be further investigated. During the preliminary design phase, the results from the conceptual phase will be verified and further detailed enabling the design team to extrapolate the requirements catalogue for the on-going procurement process.

The preliminary design phase is subdivided into seven phases almost analogue to the conceptual design process. Fig. 7 illustrates the different phases and interdependencies of the different preliminary design stages.

\section{Phase 1: Increased detail level of requirements} With the knowledge gained in the conceptual phase, the initial requirements can be re-evaluated and reviewed with respect to their feasibility and meaningfulness. During Phase 1, the previously designated meaningful set of requirements will be further specified, detailed, and extended by additional technical and functional details. As a result of intense cooperation between the end-user and the designer, a specified decision matrix of rated functional but also essential technical requirements will be generated, substantially influencing the following design process and, hence, allowing final assessment of the different designs.

\section{Phase 2: Development of operational scenario/ increased level of detail for design (platform, sensor and effector suite, ship equipment)}

The basic operational scenario and environment have already been designated in the initial phase of the planning process. In order to start the evaluation of the military performance of the preliminary design, a detailed operational concept has to be developed. This step mostly requires the input of the procuring authority/end user and contains information related to the potential threat, mission environment, and logistic requirements.

Based on the functional requirements specified in Phase 1, a more detailed selection for the platform, the mission systems, and the ship equipment can be made. Details for the platform contain the generation of a 3D hull model, 2D outfitting and super structure, strength calculation, basic weight estimation, and determination of stability. Technical solutions and arrangement of the components will be further specified for the mission system, as well as for the propulsion, electric, and ship operations system. In some cases, a selection decision can be made; in other cases, resulting alternating or competing technical solutions will lead to new preliminary designs.

Phase 3: Generation of $3 D$ model/manning concept/cost estimation/cost risk analysis risk analysis for payloads/ship equipment

In this phase, several steps will take place simultaneously. Generation of 3D models, along with further specifications of the manning concept will directly lead to the conceptual design, whereas the cost estimation and the risk analysis might have an effect on the design, but will mainly be required at later stages.

A special tool developed by MTG is used for the cost estimation at this step, different from the conceptual design phase, as more details 
that influence the cost estimation exist. The GELIMAKO tool is a bottom-up calculatory approach that uses engineering build-up, which is possible with detailed knowledge of the project and the design. GELIMAKO also incorporates different currencies, individual inflation rates per cost element, and price adjustment clauses.

\section{Phase 4: Generation of preliminary design}

The preliminary design eventually generated at this stage contains a 3D model, a detailed interior arrangement plan, a detailed equipment list, and a thorough cost estimation also specifying the expected life cycle costs.

\section{Phase 5: Evaluation of military performancel effectiveness}

Based on the operational environment, as defined in Phase 2, the different designs will be analysed for their military performance in a predefined operational scenario by using the MaSST simulation tool. Thereafter, detailed information can be given to the effectiveness of the sensor set, the effector set, and the platform itself.

In addition to the military performance, other characteristics will need to be analysed. Those characteristics include analysis of the signature (magnetic, acoustic etc.), analysis of vulnerability, hydrodynamic characteristics, mission capabilities and sustainability, as well as the overall performance of the sensor effector functional chain.

For this phase, MTG uses its own self-developed software tools, which is owed to the fact that almost no commercially available and only some proprietary software exist for this task.

\section{Phase 6: Assessment of different designs/ solutions}

As in the assessment process of the conceptual design phase, the preliminary designs will be evaluated utilizing the decision matrix generated in Phase 2 in combination with the results of the AHP procedure with the "Expert Choice" tool. As a result, the procurement authority will obtain a list of the degree of requirements fulfilment and a cost benefit ratio comparison of the different designs. With these tools, the procuring authority is put in a position to either make a final selection or to continue the investigation/design process.

\section{Phase 7: Documentation}

Once the final selection has been made, the technical and functional characteristics can be derived from the preliminary design. From these documents, the Statement of Requirements containing technical specifications for invitations to tender can be prepared in a very short time, which enables the procuring authority to specify the ship and evaluate the technical and commercial proposals received from the naval industry.

\section{MKS180 (Multirole Combat Ship Class 180)}

Using a standardized and flexible multi-stage design process like VORGES will allow rapidly generating statements concerning the technical and operational feasibility. Additionally, it will be possible to investigate solutions and concepts based on different formal and informal requirements. The MKS180 project is a very good example to show the advantages of VORGES in a real-time scenario to find a complex design, balancing user requirements with the budget available.

\section{History}

MKS180 is one of many German Navy design projects for which MTG Marinetechnik has been responsible. It is a project to define a frigate design meeting current and forthcoming naval requirements and political preferences. Throughout the process, the basic requirements have been changed several times resulting in over 20 different designs and over 60 design alterations at different detail levels.

Within the first two years a total of 18 conceptual designs have been generated to consolidate the basic requirements. At the end of that phase, the procuring authority in cooperation with the Navy has made an intermediate selection, allowing intensifying the process and starting the preliminary design phase. The following period was mainly used to generate the preliminary 
Table 1. MKS180 process

\begin{tabular}{|c|c|c|c|}
\hline Period & Version & Type of design & Focus / Framework \\
\hline \multirow{11}{*}{ Year 1} & $\mathrm{CD} 1$ & \multirow{18}{*}{ Conceptual } & Initial start, design to budget \\
\hline & $\mathrm{CD} 2$ & & \\
\hline & $\mathrm{CD} 5$ & & \\
\hline & CD6 & & Investigation of different variants of mission system on $\mathrm{K} 310$ platform \\
\hline & $\mathrm{CD} 7$ & & \\
\hline & CD8 & & \\
\hline & CD3 & & \\
\hline & $\mathrm{CD} 4$ & & \\
\hline & CD9 & & Investigation of different hull forms of mission system analogue to K310 \\
\hline & CD10 & & \\
\hline & CD11 & & Design with focus on modular mission system and organic assets \\
\hline \multirow{7}{*}{ Year 2} & CD15 & & Design according to military building standards \\
\hline & CD1 & & Design according to civilian building standards plus military add-ons \\
\hline & CD17 & & \multirow{2}{*}{ Conceptual designs based on updated requeriments catalogue } \\
\hline & CD18 & & \\
\hline & CD12 & & Design to budget (civil platform plus basic mission systems) \\
\hline & CD13 & & Design to budget (civil platform plus advance mission systems) \\
\hline & CD14 & & Design to budget (military platform plus advance mission systems) \\
\hline \multirow{3}{*}{ Year 3} & PD1 & \multirow{5}{*}{ Preliminary } & Design to budget \\
\hline & PD2 & & Design to requeriments \\
\hline & PD3 & & Design to budget \\
\hline \multirow{2}{*}{ Year 4} & PD4 & & - \\
\hline & PD5 & & - \\
\hline
\end{tabular}

designs and carry out many other studies related to the project.

\section{Results / Designs}

The starting point for the project was the K130 design. Initially designated K131, MTG began to create several preliminary studies analysing the influence of using either civilian or military or a combination of both building standards on the overall complex system of a naval vessel to get a first feeling of the influence on prices and military performance.

Based on the initial very basic requirements, MTG started generating first designs and several preliminary studies. The resulting conceptual designs were primarily made to elaborate different designs on one side for different hullforms and different variants of the mission system on the other side. Independent of those designs, MTG made a design to investigate the influence of a high-end modular system on capabilities and price. After the selection of the hullform and the mission system, five designs were done on a design to budget or design to requirement and design according to civilian plus military add-ons or military building standard basis. During this phase a grand total of 18 conceptual designs have been finished and many different aspects have been investigated enabling the procuring authority and respective project management to consolidate the basic requirements and to adapt existing designs to changing military but also to civilian rules and regulations. 
Fig. 6. Price trend during MKS180 process, including lower and upper budget restrictions

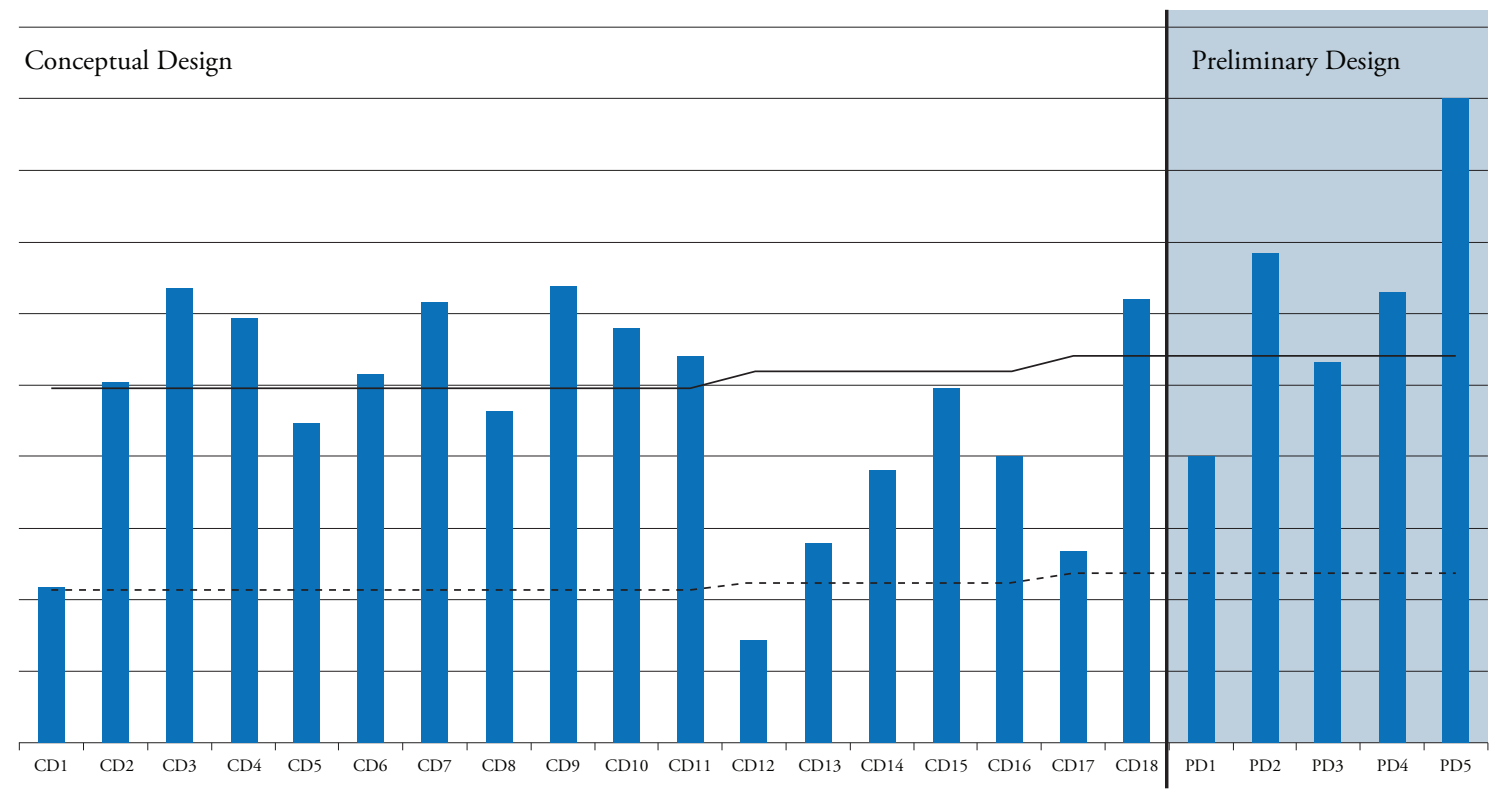

Until now, MTG has made a total of five preliminary designs based on the results of the conceptual design phase and the results of the preceding design. It was the VORGES methodology that allowed this complex investigation under the different frameworks that were either driven by changing naval requirements or by changing focuses of investigation.

During the overall process, the budget and the requirements had to be adapted as it was the procurement authorities/Navies' decision to proceed with a military design and a sophisticated modular mission system. The drawbacks of using a civilian design standard with military add-ons were not acceptable to the Navy.

This decision could fundamentally be made based on information gained during the conceptual and preliminary design phase.

Fig. 7 is a good example to show the influence of the different designs for the overall project. During the process, the Navy gained so much information and changed/extended the requirements that the displacement increased during the project to almost four times, compared to the beginning.
As mentioned earlier, based on the requirement to proceed with a military design standard, the budget had to be adapted several times throughout the project. Figure 6 gives a good overview of the tendency and price development of the several designs.

With PD5 finished recently, the procurement authority along with the Navy is now able to determine the final value for the defence budget and about to formulate the technical requirements that will be given to the industry to start the initial tender process.

\section{Conclusions}

During most naval procurement projects, the allocated budget is not sufficient to meet all requirements. For this matter, it is essential to have a methodology to generate numerous designs in a very short time balancing the different requirements. This enables the procuring authority to select from a set of different designs the one that meets the requirements at the highest level. VORGES, the procedural model for total ship system engineering, has been developed by MTG Marinetechnik as an iterative process for the conceptual and preliminary 
Fig. 7. Development of displacement during the MKS180 process

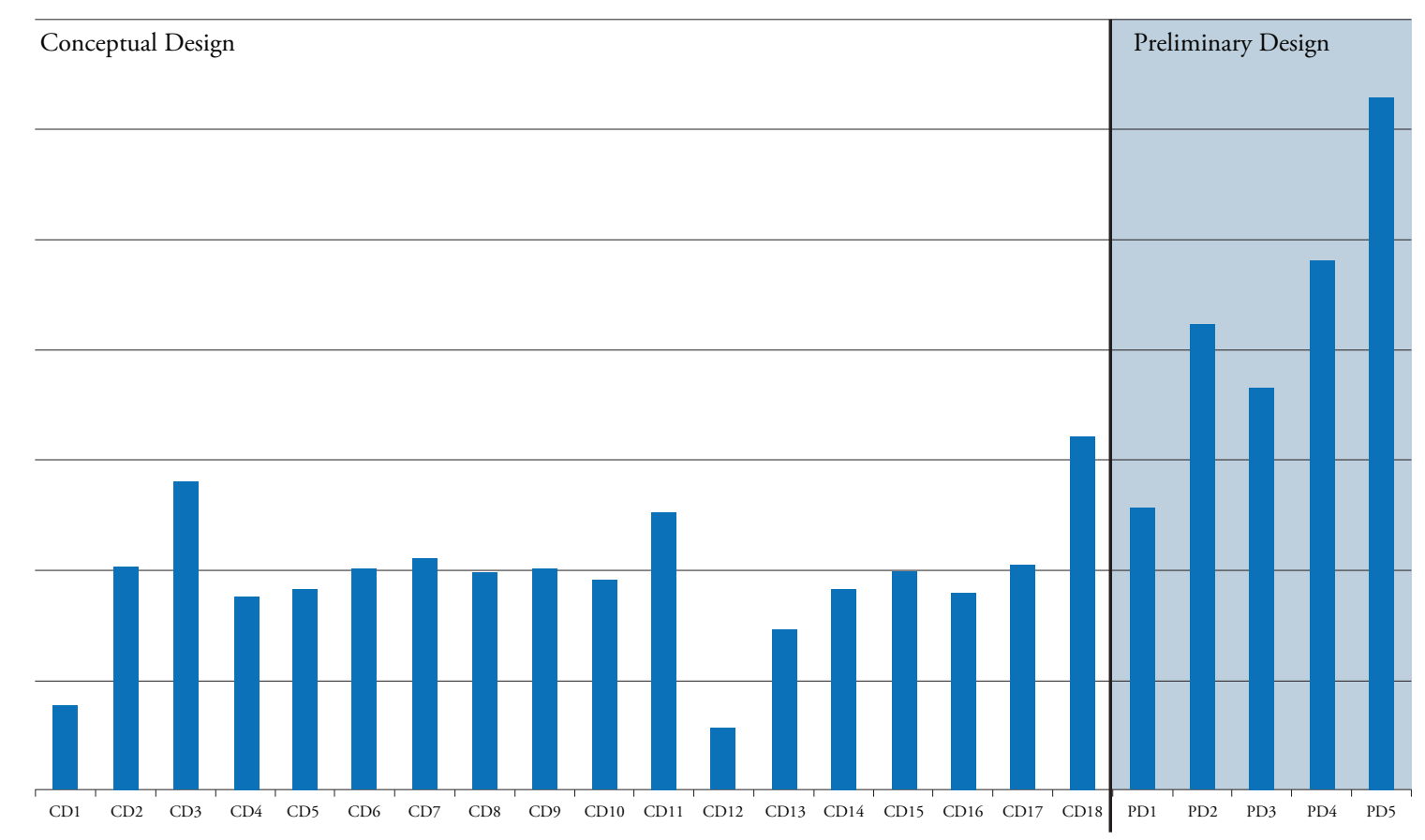

design of surface naval vessels in the early planning phases. During the iterative design process, the requirements and costs are constantly evaluated allowing the early adjustment of either the budget or the requirements. Additionally, all designs will be evaluated for their military performance and assessed for their requirements fulfilment, thus, greatly reducing the complexity of the decision for the procuring authority. The ability and high flexibility to generate several different designs will enable the procuring authority to decide whether to continue the planning process or to start the formulation of the technical requirements that will then be forwarded to the naval industry. The flexibility and agility of the VORGES model will enable the design agency to rapidly adapt to any changes of functional requirements or rules and regulations that usually and almost invariably occur during the overall planning process.

The latest frigate design project, MKS180, is a good example to show the capabilities of the VORGES methodology. During the process, several designs have been generated in a very short period of time to look at all facets of probable solutions, designs, and design combinations. As one result of the learning process, the Navy along with the procurement authority repeatedly updated the budget, as well as the functional requirements several times and has finally been in a position to proceed with a design meeting military requirements to a maximum extent, which emerged as the latest PD5 design. Hamburg, January 2013

\section{Author's biography}

ANDRÉ NEUMANN joined the Systems Engineering Team at MTG Marinetechnik GmbH in 2012. He served for 15 years as a naval aviation officer in the German Navy, followed by 4 years in the maritime industry as a Project- and Key Account Manager. He holds an advanced degree in business administration and economics.

\section{Bibliography}

www.mtg-marinetechnik.de 